\title{
Post-synthesis stabilization of germanosilicate zeolites ITH, IWW and UTL by substitution of Ge for Al
}

\author{
Mariya V. Shamzhy, ${ }^{a^{*}}$ Pavla Eliašová, ${ }^{b}$ Dana Vitvarová, ${ }^{a}$ Maksym V. Opanasenko, ${ }^{b}$ Daniel S. Firth, ${ }^{c}$ \\ Russell E. Morris ${ }^{c}$
}

\begin{abstract}
Germanosilicate zeolites often suffer from low hydrothermal stability due to the high content of Ge. Here we investigated the post-synthesis introduction of Al accompanied with stabilization of selected germanosilicates by degermanation/alumination treatments. The influence of chemical composition and topology of parent germanosilicate zeolites (ITH, IWW and UTL) on the post-synthesis incorporation of Al was studied. Alumination of ITH $(\mathrm{Si} / \mathrm{Ge}=2-13)$ and IWW $(\mathrm{Si} / \mathrm{Ge}=3-7)$ zeolites resulted in the partial substitution of $\mathrm{Ge}$ for $\mathrm{Al}$ (up to $80 \%$ ) enhancing with decrease $\mathrm{Ge}$ content in the parent zeolite. In contrast, in extra-large pore zeolite UTL $(\mathrm{Si} / \mathrm{Ge}=4-6)$ the hydrolysis of the interlayer $\mathrm{Ge}-\mathrm{O}$ bonds dominated over substitution. The stabilization of zeolite UTL was achieved using novel 2-step degermanation/alumination procedure by the partial post-synthesis substitution of Ge for Si followed by alumination. This new method of stabilization and incorporation of strong acid sites may extend the utilization of germanosilicate zeolites, which has been until now limited.
\end{abstract}

\section{Introduction}

During the last decade germanosilicate zeolites have attracted a lot of attention. Germanium acts as an inorganic structuredirecting agent (SDA) with a particular selectivity towards frameworks containing Ge-enriched double-four-ring (D4R) units. ${ }^{[1]}$ The stabilization of small-rings by Ge has allowed for the synthesis of many new structures such as BEC, ${ }^{[1 a, 2]} \mathbf{A S V},{ }^{[3]}$

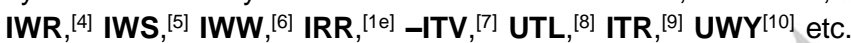
The hydrolytic instability of $\mathrm{Si}-\mathrm{O}-\mathrm{Ge}$ and $\mathrm{Ge}-\mathrm{O}-\mathrm{Ge}$ linkages, combined with the regioselective location of $\mathrm{Ge}$ atoms in D4R units, ${ }^{[11]}$ has enabled the development of a new top-down strategy. The selective disassembly of germanosilicates like $\mathbf{U T L}^{[12]}$ and IWW, ${ }^{[13]}$ containing unidirectional hydrolytically unstable D4R units, has allowed the formation of new layered zeolitic materials. In contrast the hydrolysis of frameworks containing Ge-enriched D4Rs in three directions (e.g. BEC, ${ }^{[1 a]}$ IWS, ${ }^{[5]} \mathbf{I R R},{ }^{[1]}{ }^{10]} \mathbf{S T W},{ }^{[14]}$ etc.) results in full fragmentation, even in

[a] Dr. Mariya V. Shamzhy, Dr. Dana Vitvarová

Department Synthesis and Catalysis

J. Heyrovský Institute of Physical Chemistry of the Czech Academy

of Sciences, v. v. i.

Dolejškova 3, CZ-182 23 Prague 8, Czech Republic

E-mail: mariya.shamzhy@jh-inst.cas.cz

[b] Dr. Pavla Eliašová, Dr. Maksym V. Opanasenko

Department of Physical and Macromolecular Chemistry, Faculty of Science

Charles University in Prague

Hlavova 2030, 12840 Prague 2, Czech Republic

[c] Daniel S. Firth, Prof. Russell E. Morris

EaStCHEM School of Chemistry

University of St. Andrews

St. Andrews KY16 9ST (UK)

Supporting information for this article is given via a link at the end of the document. ambient air moisture.

Due to the presence of small structural units (e.g. D4R, $\mathrm{D} 3 \mathrm{R})$ the frameworks of germanosilicates are generally characterized by low densities (up to $10.5 \mathrm{~T} / 1000 \AA^{3}$ ) and high pore volumes (accessible volume up to $40 \%$ ), making them especially suitable in processing bulky molecules. ${ }^{[1 c]}$ However, the low hydrothermal stability and high cost of Ge significantly limits the practical use of Ge-containing zeolites.

The post-synthesis replacement of framework cations, commonly applied to calcined SDA-free zeolites, is frequently not acceptable for germanosilicate zeolites, due to their inability to withstand high temperature treatment. Thus, the postsynthesis stabilization of SDA-containing germanosilicate zeolites was attempted. It has been reported that, under low acidic conditions, aluminium could be incorporated into the BEC $(\mathrm{Si} / \mathrm{Ge}=3.6)$ framework with the simultaneous removal of $\mathrm{Ge}$ and SDA. ${ }^{[15]}$ The substitution of $\mathrm{Ge}$ for $\mathrm{Si}$ under highly acidic conditions was recently reported for as-synthesized IWW, ${ }^{[16]}$ IWR, BEC, UWY and UTL ${ }^{[17]}$ zeolites. Previously we reported new approaches to tune the strength of acid sites through the post-synthesis treatment of IWR and ITH zeolites. ${ }^{[18]}$

To the best of our knowledge, the stabilization and functionalization of the extra-large pore zeolite UTL, through the post-synthesis incorporation of aluminium, has not been examined. Moreover, up-to-now post-synthesis introduction of acid centers to the frameworks of IWW and ITH zeolites was succeeded only for a limited chemical compositions - using Gepoor samples for former case and Ge-rich samples for latter zeolite. Therefore, in this contribution we assess the influence of crucial parameters of parent materials (framework type, chemical composition, presence of the SDA in the channels, etc.) and treatment conditions on the stability and the extent of Ge for Al substitution in UTL, ITH, IWW zeolites of different Gecontent.

\section{Results and Discussion}

Parent germanosilicate zeolites

The topologies of zeolites ITH, IWW, UTL are similar as they can all be viewed as dense two-dimensional (2D) layers separated by D4R bridging units enriched with Ge (Figure 1). Ge atoms (almost $95 \%$ ) were found to preferentially occupy $T$ sites within the D4R units of UTL, ${ }^{[8]}$ IWW $^{[19]}$ and Ge-poor $(\mathrm{Si} / \mathrm{Ge}>5)$ ITH. ${ }^{[20]}$ Ge-rich ITH also has up to $50 \%$ Ge occupation in the $\left[4^{1} 5^{2} 6^{2}\right]$ cages in the layers. ${ }^{[20-21]}$ The chemical composition of UTL prepared from reaction mixtures with different $\mathrm{Si} / \mathrm{Ge}$ molar ratio was found to vary between $3.8-6.7 .^{[8,22]}$ The molar ratio $\mathrm{Si} / \mathrm{Ge}=4.5$ corresponds to $7 \mathrm{Ge}$ atoms per $\mathrm{D} 4 \mathrm{R}$ unit $(7 \mathrm{Ge}, 1 \mathrm{Si}) .{ }^{[8 \mathrm{a}]}$ With a higher $\mathrm{Si} / \mathrm{Ge}$ molar ratio $(\mathrm{Si} / \mathrm{Ge}=6.7)$ the average number of $\mathrm{Ge}$ atoms decreases to 5 per $\mathrm{D} 4 \mathrm{R}$ unit 
(5Ge,3Si). Upon the hydrolysis of Ge-rich UTL ( $\mathrm{Si} / \mathrm{Ge}=5.1$ ) only a narrow signal ca. $\sim 10 \mathrm{ppm}$ in the ${ }^{19} \mathrm{~F}$ NMR spectrum was observed. This indicated the exclusive formation of $(\mathrm{SiO})_{3} \mathrm{SiOH}$ and the presence of one germanate four-ring in each D4R unit $(4 \mathrm{Ge}, 4 \mathrm{Si})$ in the parent germanosilicate. ${ }^{[23]}$
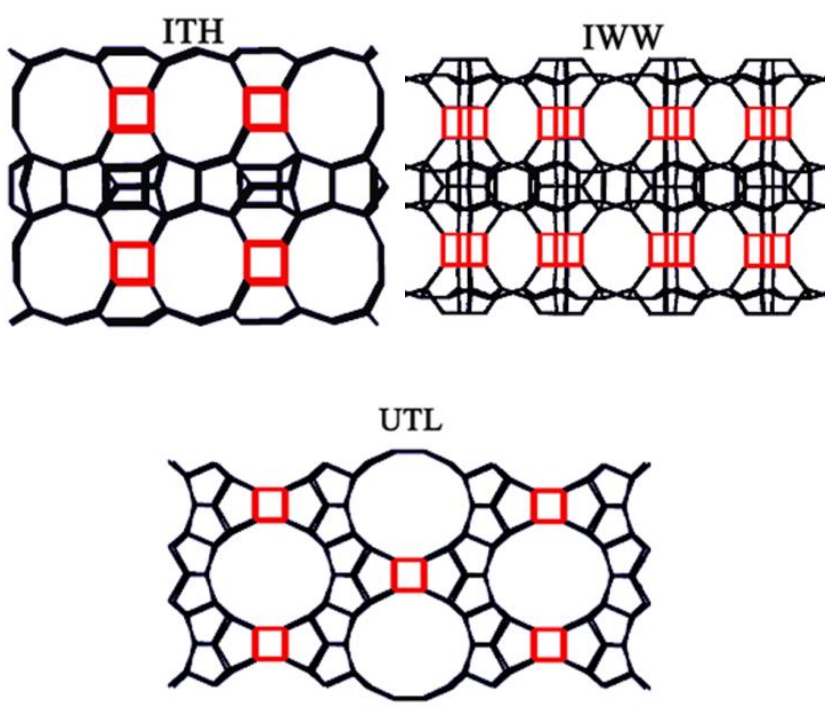

Figure 1. Structure of zeolites ITH (010 projection), IWW (010 projection), UTL (001 projection).

In order to vary the chemical composition of parent materials, we prepared a series of UTL, IWW and ITH zeolites including their Ge-poor and Ge-rich forms (Table 1). Ge-rich zeolites had $\mathrm{Si} / \mathrm{Ge}$ ratios in the range 2.3 - 3.8, while Ge-poor samples were characterized by $\mathrm{Si} / \mathrm{Ge}$ ratios $6.0-13.3$. XRD patterns of all as-synthesized samples matched well with those reported in the literature indicating a high degree of crystallinity and phase purity (Figure S1, Supporting information).

Table 1. Chemical composition and textural properties of parent germanosilicates.

\begin{tabular}{|c|c|c|c|c|c|c|}
\hline \multirow[t]{2}{*}{ Sample } & \multicolumn{2}{|c|}{$\begin{array}{l}\text { Chemical } \\
\text { composition,mol. } \\
\%\end{array}$} & \multirow[t]{2}{*}{$\mathrm{Si} / \mathrm{Ge}$} & \multirow[t]{2}{*}{$\begin{array}{l}\text { Crystal size } \\
(\mu \mathrm{m})\end{array}$} & \multirow[t]{2}{*}{$\begin{array}{l}V_{\text {micro }} \\
\mathrm{cm}^{3} \cdot \mathrm{g}^{-}\end{array}$} & \multirow[t]{2}{*}{$\begin{array}{l}V_{\text {total }} \\
\mathrm{cm}^{3} \cdot \mathrm{g}^{-1}\end{array}$} \\
\hline & $\mathrm{Si}$ & $\mathrm{Ge}$ & & & & \\
\hline ITH-13 & 93.0 & 7.0 & 13.3 & $5 \times 0.5 \times 0.5$ & 0.12 & 0.20 \\
\hline ITH-2 & 69.7 & 30.3 & 2.3 & $15 \times 1 \times 0.5$ & 0.13 & 0.18 \\
\hline IWW-7 & 87.8 & 12.2 & 7.2 & $0.5-1$ & 0.16 & 0.30 \\
\hline IWW-3 & 74.4 & 25.6 & 2.9 & $0.5-1$ & 0.17 & 0.30 \\
\hline UTL-6 & 85.7 & 14.3 & 6.0 & $\begin{array}{l}25 \times 20 \times \\
0.1\end{array}$ & 0.21 & 0.24 \\
\hline UTL-4 & 79.1 & 20.8 & 3.8 & $\begin{array}{l}30 \times 20 \times \\
0.1\end{array}$ & 0.19 & 0.20 \\
\hline
\end{tabular}

All zeolites under investigation exhibit a type I isotherm in gas adsorption experiments (Figure S2, Supporting information) with a steep increase in the amount adsorbed at low relative pressures $\left(p / p_{0}<0.01\right)$ indicating filling of the micropores. The micropore volumes decreased in the order: UTL $(0.19-0.21$ $\left.\mathrm{cm}^{3} \cdot \mathrm{g}^{-1}\right)>$ IWW $\left(0.16-0.17 \mathrm{~cm}^{3} \cdot \mathrm{g}^{-1}\right)>$ ITH $\left(0.12-0.13 \mathrm{~cm}^{3} \cdot \mathrm{g}^{-}\right.$ 1) (Table 1) reflecting the different pore dimensions of the zeolites: 14-12-ring (UTL) > 12-10-8-ring (IWW) > 10-10-9-ring (ITH).

ITH zeolite formed platelet-like crystals (Figure 2A and B) in which the sinusoidal $10-\mathrm{R}$ channel goes along the $\mathrm{C}$-axis with a length of $5-15 \mu \mathrm{m}$ (Table 1 ), whereas the other 10- and the 9-R channels occur along the $a-b$ plane $\left(0.5-1 \mu \mathrm{m}\right.$, Table 1). ${ }^{[24]}$ In contrast, IWW showed small crystals between $0.5-1 \mu \mathrm{m}$ crystallizing in agglomerates (Figure $2 \mathrm{C}$ and $\mathrm{D}$ ). UTL zeolites formed quite uniform thin rectangular crystals in which 12- and $14-R$ channels occur along $b-c$ plane $(25-30 \times 20 \mu \mathrm{m}$, Table 1), while the shortest dimension of the crystal $(0.1 \mu \mathrm{m}$, Table 1) goes along $a$ axis (Figure 2E and F).[25]
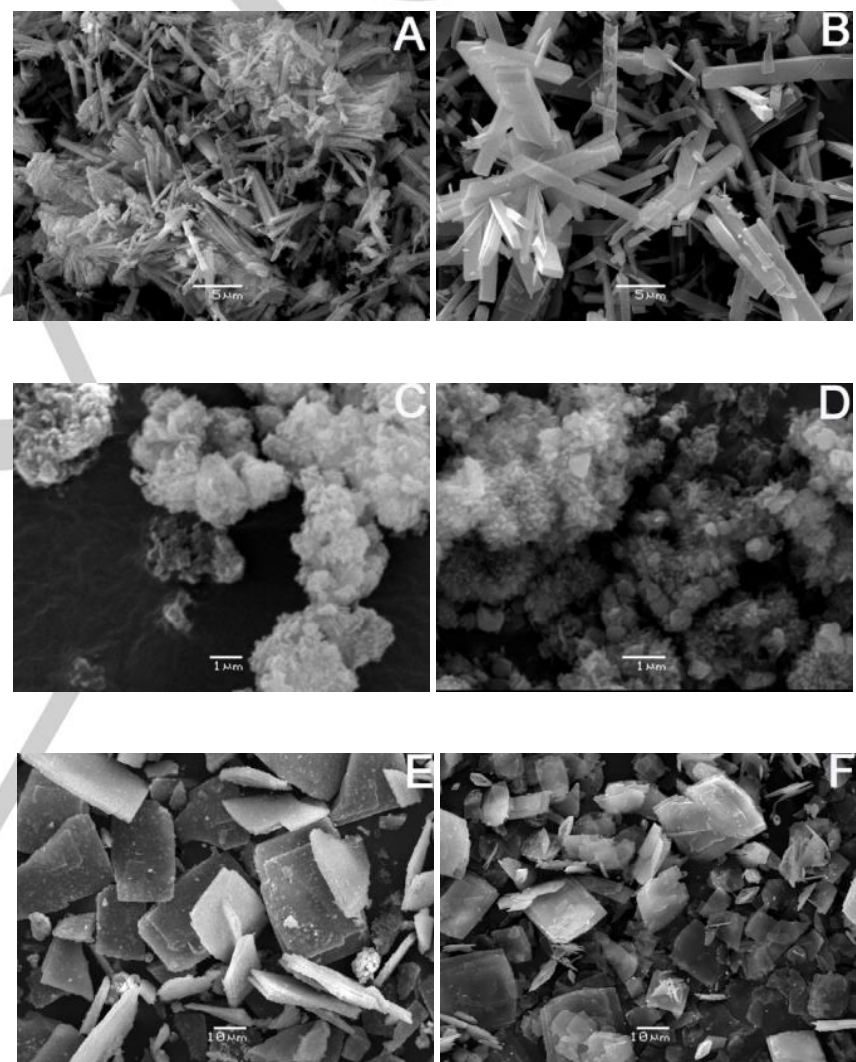

Figure 2. SEM images of germanosilicate zeolites: ITH-13 (A), ITH-2 (B), IWW-7 (C), IWW-3 (D), UTL-6 (E), and UTL-4 (F).

Although thermally stable germanosilicates under investigation demonstrated a low hydrolytic stability: only Gepoor ITH and IWW zeolites maintained the structural ordering upon the treatment with $0.01 \mathrm{M} \mathrm{HNO}_{3}$ at $\mathrm{pH}=2$ (Figure 3) corresponding to the standard post-synthesis substitution of $\mathrm{Ge}$ for Al procedure (e.g. the treatment of calcined zeolite with $1 \mathrm{M}$ $\mathrm{Al}\left(\mathrm{NO}_{3}\right)_{3}$ solution $(\mathrm{pH}=2)$ at $80^{\circ} \mathrm{C}$ for $\left.24 \mathrm{~h}\right)^{[26]}$. This method of alumination was chosen as a basic treatment approach since it is performed under conditions preventing mobility of framework $\mathrm{Si}$ atoms due to formation of either cationic or anionic species (isoelectric point of silica lies in the range $\mathrm{pH}=1.5-3.5$ ). ${ }^{[27]}$ The results of alumination indicated that $\mathrm{Al}$ prevents the destruction 
of Ge-rich ITH and IWW frameworks in acidic medium (Figure 3). Ge-rich ITH and IWW zeolites subjected to alumination showed a drop in $\mathrm{Ge}$ concentration while maintaining their structure ordering despite the treatment at $\mathrm{pH}=2$.

Incorporated Al generated both Brønsted and Lewis acid sites in calc/TH/Al and calc/WW/Al (vide infra). However the presence of $\mathrm{Al}$ in the medium did not increase the hydrolytic stability of UTL, which was destroyed during the alumination treatment (Figure 3C).
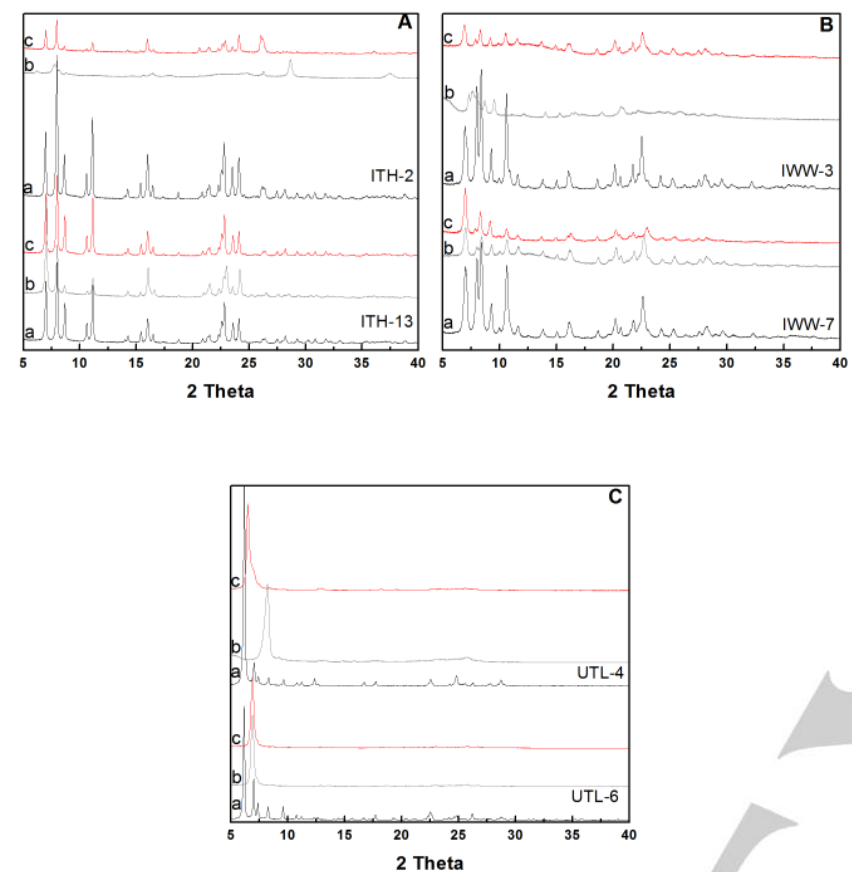

Figure 3. XRD patterns of ITH (A), IWW (B), UTL (C): calcined zeolites (a), zeolites treated with $0.01 \mathrm{M} \mathrm{HNO}_{3}$ solution at $\mathrm{T}=25^{\circ} \mathrm{C}$ for $\tau=24 \mathrm{~h}(\mathrm{~b})$, calcZeolite/Al (c)

We hypothesize two reasons for the lack of UTL stabilization via the standard alumination technique. 1) The critically lower rate of $\mathrm{Al}\left(\mathrm{H}_{2} \mathrm{O}\right)_{6}{ }^{3+}$ diffusion vs. degermanation in the channels occurring along $b-c$ plane of the crystals $(25-30 x$ $20 \mu \mathrm{m}$, Table 1). 2) The specific arrangement of $\mathrm{Ge}$ in the D4Rs of UTL (i.e. the presence of a Ge-pure S4R units within D4Rs ${ }^{[23]}$ ). This restricts the substitution of $\mathrm{Ge}$ for Al. In contrast, diffusion limitations do not seem to limit the substitution of $\mathrm{Ge}$ for $\mathrm{Al}$ in ITH and IWW (vide infra). Both formed tiny crystals (Figure 2 A$\mathrm{D}$, Table 1) and are characterized by three-dimensional pore systems.

Therefore, a set of modified alumination procedures were attempted for UTL. As-synthesized SDA-containing UTL was used in three different procedures: a one-step post-synthesis alumination with $\mathrm{Al}\left(\mathrm{NO}_{3}\right)_{3}$ (Scheme 1, procedure 3) and a twostep substitution via consecutive degermanation/alumination in TEOS-free (Scheme 1, procedure 4) and TEOS-containing mixtures (Scheme 1, procedure 5). The latter technique was also applied for calcined zeolites (Scheme 1, procedure 2). The idea to use SDA-containing zeolites as starting materials was based on the possible stabilization of the zeolite framework by organic molecules occluded in the pores, previously shown for BEC ${ }^{[15,28]}$ TEOS was intentionally used to stabilize the D4Rs by their enrichment with Si. To address the influence of zeolite topology and chemical composition on the outcome of postsynthesis Al incorporation, we also applied the modified alumination procedures to the other germanosilicates under investigation.

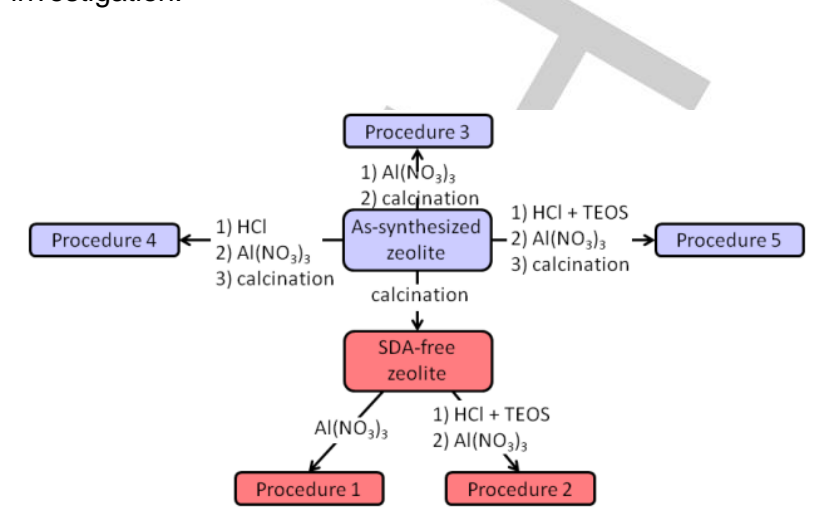

Scheme 1. Post-synthesis alumination of germanosilicate zeolites: procedures.

\section{Post-synthesis treatment}

As-synthesized UTL zeolites. The treatment of SDA-containing UTL with $\mathrm{Al}\left(\mathrm{NO}_{3}\right)_{3}$ solution $(\mathrm{pH}=2$, procedure 3 , Scheme 1 ) did not cause any structural transformation of the framework (Figure 4). However the prepared asUTL/Al samples showed a relatively low degree of degermanation and no $\mathrm{Al}$ incorporation. EDX analysis showed a slight increase in $\mathrm{Si} / \mathrm{Ge}$ from 6.0 to 6.2 and 3.8 to 5.1 for Ge-poor and Ge-rich UTL respectively (Table S2, Supporting information).
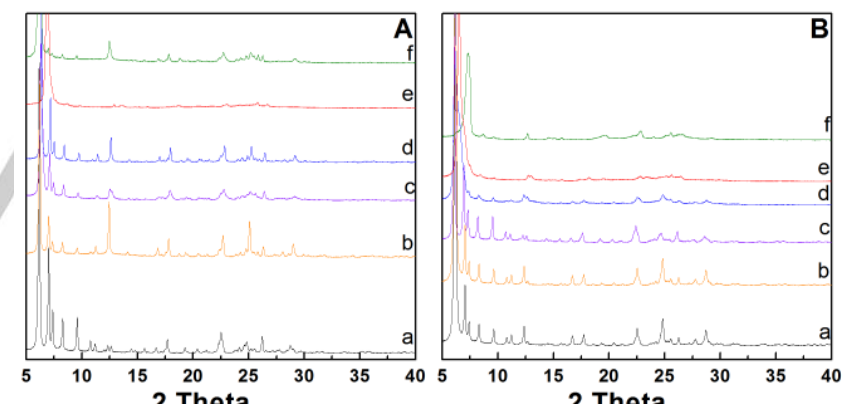

Figure 4. XRD patterns of UTL-6 (A) and UTL-4 (B): calcined zeolites (a) asUTL/Al/calc (b), asUTL/HCl/Al/calc (c), asUTL/HCl+TEOS/Al/calc (d), calcUTL/Al (e), calcUTL/HCl+TEOS/Al (f).

asUTL/Al/calc samples showed a similar concentration of silanol groups (absorption band at $3745 \mathrm{~cm}^{-1}$ in FTIR spectra, Figure 5) as the parent UTL zeolite. The treatment of SDA-containing UTL with a $1 \mathrm{M} \mathrm{HCl}$ solution under hydrothermal conditions led to a twofold increase in the $\mathrm{Si} / \mathrm{Ge}$ ratios for both $\mathrm{Ge}$-poor $(\mathrm{Si} / \mathrm{Ge}=$ 11.8 and 6 for asUTL-6/HCl/Al/calc and UTL-6/calc, respectively) and Ge-rich UTL $(\mathrm{Si} / \mathrm{Ge}=10.3$ and 3.8 for asUTL$4 / \mathrm{HCl} / \mathrm{Al} / \mathrm{calc}$ and UTL-4/calc, respectively). With analysis showing an increase in the intensity of the absorption band at $3745 \mathrm{~cm}^{-1}$ in FTIR spectra (Figure 5). These results indicate a partial extraction of $\mathrm{Ge}$ atoms (i.e. breaking of unstable Si-OGe linkages) from the SDA-containing germanosilicate zeolites under acidic conditions. XRD analysis confirmed the 
preservation of the structure of asUTL-6/HCl (Figure S3, Supporting information) and the collapse of the asUTL-4/HCl framework. This was due to the higher number of $\mathrm{Ge}$ atoms present in the framework, which have to be replaced by Si from the partial dissolution of the dense layers at $\mathrm{pH} \approx 0^{[17,29]}$ to maintain the structural ordering of UTL. By introducing an additional silica source at highly-acidic medium during the degermanation step we were able to preserve the UTL-4 framework (Figure S3, Supporting information), while increasing the $\mathrm{Si} / \mathrm{Ge}$ ratio from 3.8 to 7.0 when compared with the parent zeolite (Table S2, Supporting information). This was confirmed by FTIR as degermanated asUTL samples in the presence of TEOS showed a lower concentration of silanol groups than asUTL/HCl/Al/calc (Figure 5).
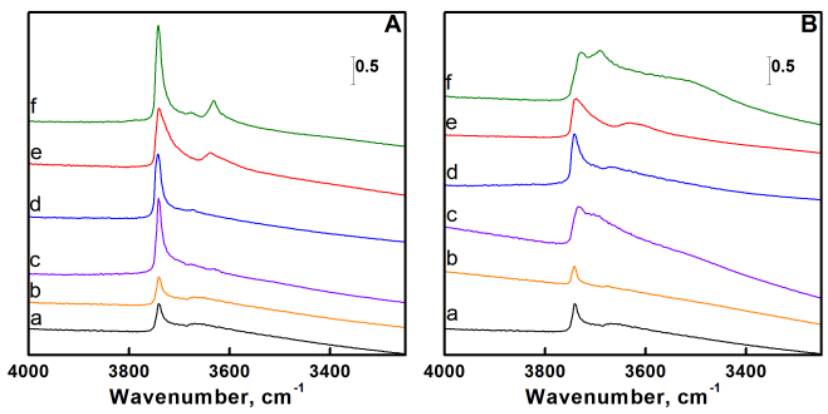

Figure 5. FTIR spectra of UTL-6 (A) and UTL-4 (B) zeolites in region of hydroxyl vibrations: calcined zeolites (a), asUTL/Al/calc (b), asUTL/HCl/Al/calc (c), asUTL/HCl+TEOS/Al/calc (d), calcUTL/Al (e), calcUTL/HCl+TEOS/Al (f).

Further alumination of asUTL-6/HCl, asUTL-6/HCl+TEOS and asUTL-4/HCl+TEOS did not cause any decrease in the crystallinity of samples (Figure S3, Supporting information). However only a small amount of Al generating Brønsted and Lewis acid centers were incorporated in asUTL-6 when degermanated with hydrochloric acid $\left(62 \mu \mathrm{mol} \mathrm{g}{ }^{-1}\right.$, Table S2, Supporting information). No $\mathrm{Al}$ was found in asUTL$6 / \mathrm{HCl}+T E O S / A / / c a l c$. This result may be connected with preferential healing of silanol nests with $\mathrm{Si}$ in the presence of TEOS.

SDA-free UTL zeolites. To increase access to the entire volume of UTL by the substituting ion and to overcome the restrictions imposed on the substitution of $\mathrm{Ge}$ for $\mathrm{Al}$ by the presence of $\mathrm{Ge}-\mathrm{O}-\mathrm{Ge}$ bonds in $\mathrm{D} 4 \mathrm{R}$ units we attempted the consecutive degermanation of an SDA-free zeolite in the presence of a Si source, to initiate partial substitution of $\mathrm{Ge}$ for $\mathrm{Si}$, followed by alumination (Scheme 1 , procedure 2). It was found that, unlike SDA-containing UTL-4 zeolite, treatment of calcined UTL-4 with an ethanolic HCl/TEOS mixture, followed by alumination resulted in the destruction of the zeolite framework (Figure 4 and Figure S4, Supporting information). The maintenance of the asUTL-4 framework after treatment with the $\mathrm{HCl} / \mathrm{TEOS}$ mixture may be due to the presence of SDA cations, which causes a deceleration in the hydrolysis of $\mathrm{Ge}-\mathrm{O}$ bonds. Indeed the asUTL-4/HCl+TEOS/A/ sample showed a remarkably lower drop in Ge concentration (40\% of Ge leached, Table S2, Supporting information) in comparison to calcUTL$4 / \mathrm{HCl}+\mathrm{TEOS} / \mathrm{Al}(87 \%$ of $\mathrm{Ge}$ leached, Table S2, Supporting information).
In contrast to two-step degermanation/alumination of $\mathrm{Ge}$ rich UTL-4, the calcUTL-6/HCl+TEOS/Al sample showed the preservation of the structure under similar degermanation/alumination conditions (Figure 4 and Figure S4 Supporting information). This may indicate the different rates of degermanation and substitution in Ge-poor samples.

${ }^{27} \mathrm{Al}$ MAS NMR spectrum of calcUTL-6/HCl+TEOS/AI showed a dominant peak at $50-80 \mathrm{ppm}$ (Figure 6). This confirmed the incorporation of $\mathrm{Al}$ into the framework positions of UTL. ${ }^{[30]}$ The introduction of Al resulted in generation of both Brønsted $\left(222 \mu \mathrm{mol} \mathrm{g}^{-1}\right)$ and Lewis $\left(364 \mu \mathrm{mol} \mathrm{g}^{-1}\right)$ acid sites in calcUTL-6/HCl+TEOS/Al (Table 2).

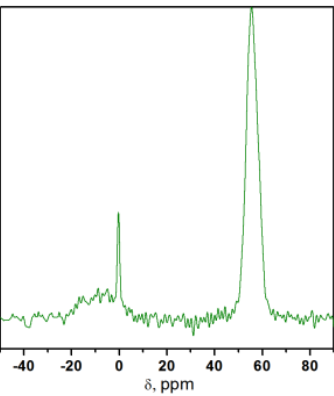

Figure 6. ${ }^{27} \mathrm{AI}$ MAS NMR spectra of calcUTL/HCl+TEOS/Al

Ar adsorption (Figure 7) showed a decrease in the micropore volume $\left(0.14\right.$ vs. $0.21 \mathrm{~cm}^{3} \cdot \mathrm{g}^{-1}$, Table 2) with a simultaneous enhancement of total pore volume $(0.36 \mathrm{vs}$. 0.24 $\mathrm{cm}^{3} \cdot \mathrm{g}^{-1}$, Table 2) in calcUTL-6/HCl+TEOS/Al vs. UTL-6. Also calcUTL-6/HCl+TEOS/Al showed the same micropore size distribution centered at $0.65 \mathrm{~nm}$ as original the UTL-6 zeolite with an additional broad size distribution of large mesopores (Figure 7B). The presence of large mesopores and macropores in calcUTL-6/HCl+TEOS/Al is most likely connected with formation of intercrystalline linkages, through the partial deposition of extra-framework silica and the non-equivalent replacement of leached $\mathrm{Ge}$ for Si/Al atoms, in the course of post-synthesis degermanation/alumination.
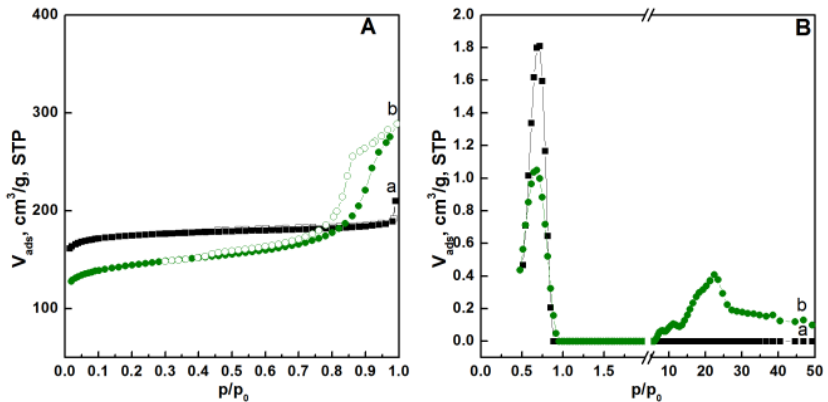

Figure 7. Argon adsorption $(\cdot)$ and desorption $(\circ)$ isotherms $(\mathbf{A})$ and pore-size distribution (B) of UTL-6 (a) and calcUTL-6/HCl+TEOS/Al (b) zeolites.

Substitution of $\mathrm{Ge}$ for $\mathrm{Si} / \mathrm{Al}$ in calcUTL-6/HCl+TEOS/Al leads to an enhancement of the hydrolytic stability of the UTL framework. In contrast to UTL-6, the treatment of calcUTL- 
Table 2. Chemical composition, textural and acidic properties of aluminated ITH, IWW and UTL zeolites.

\begin{tabular}{|c|c|c|c|c|c|c|c|c|c|}
\hline \multirow{2}{*}{ Sample } & \multirow{2}{*}{$\begin{array}{l}V_{\text {micro }} \\
\mathrm{cm}^{3} \cdot \mathrm{g}^{-1}\end{array}$} & \multirow{2}{*}{$\begin{array}{l}V_{\text {total }} \\
\mathrm{cm}^{3} \cdot \mathrm{g}^{-1}\end{array}$} & \multicolumn{2}{|c|}{ Chemical composition } & \multirow{2}{*}{$\begin{array}{l}\text { Alth }{ }^{[a]} \\
\text { mol. \% }\end{array}$} & \multirow{2}{*}{$\begin{array}{c}\Delta \mathrm{w}^{[\mathrm{b}]} \\
\%\end{array}$} & \multicolumn{3}{|c|}{$\begin{array}{l}\text { Concentration of acid sites, } \\
\mu \mathrm{mol} \mathrm{g}{ }^{-1}\end{array}$} \\
\hline & & & Al, mol. \% & $\mathrm{Si} / \mathrm{Ge}$ & & & $C_{B}$ & $C_{L}$ & $\mathrm{C}_{\Sigma}$ \\
\hline ITH-13 & 0.12 & 0.20 & - & 13 & - & & & - & - \\
\hline calclTH-13/Al & 0.14 & 0.32 & 2.0 & 20 & 1.8 & 4 & 51 & 160 & 211 \\
\hline calclTH-13/HCl+TEOS/Al & 0.05 & 0.11 & - & 17 & - & 3 & - & - & - \\
\hline ITH-2 & 0.13 & 0.18 & - & 2 & - & - & - & - & - \\
\hline calcITH-2/Al & 0.13 & 0.25 & 1.5 & 13 & 1.3 & 16 & 68 & 262 & 330 \\
\hline calcITH-2/HCl+TEOS/Al & 0.02 & 0.04 & - & 5 & . & 10 & - & - & - \\
\hline IWW-7 & 0.16 & 0.30 & - & 7 & - & - & - & - & - \\
\hline calclWW-7/Al & 0.19 & 0.39 & 7.6 & 36 & 6.4 & 9 & 346 & 411 & 757 \\
\hline calcIWW-7/HCl+TEOS/Al & 0.09 & 0.46 & 5.0 & 20 & 4.4 & 7 & 211 & 320 & 533 \\
\hline IWW-3 & 0.17 & 0.30 & - & 3 & - & - & - & - & - \\
\hline calclWW-3/Al & 0.18 & 0.52 & 7.1 & 21 & 6.1 & 15 & 284 & 427 & 711 \\
\hline calcIWW-3/HCl+TEOS/Al & 0.14 & 0.39 & 4.8 & 19 & 4.2 & 17 & 242 & 274 & 516 \\
\hline UTL-6 & 0.21 & 0.24 & - & 6 & - & - & - & - & - \\
\hline calcUTL-6/HCl+TEOS/Al & 0.14 & 0.36 & 5.7 & 39 & 5.4 & 11 & 222 & 364 & 586 \\
\hline
\end{tabular}

[a] calculated based on the integral intensities of peaks at 0 and $60 \mathrm{ppm}$ in ${ }^{27} \mathrm{Al}$ NMR spectra

[b] weight reduction after alumination $[\mathrm{m}$ (parent) $-\mathrm{m}$ (aluminated) $] / \mathrm{m}$ (parent) • $100 \%$
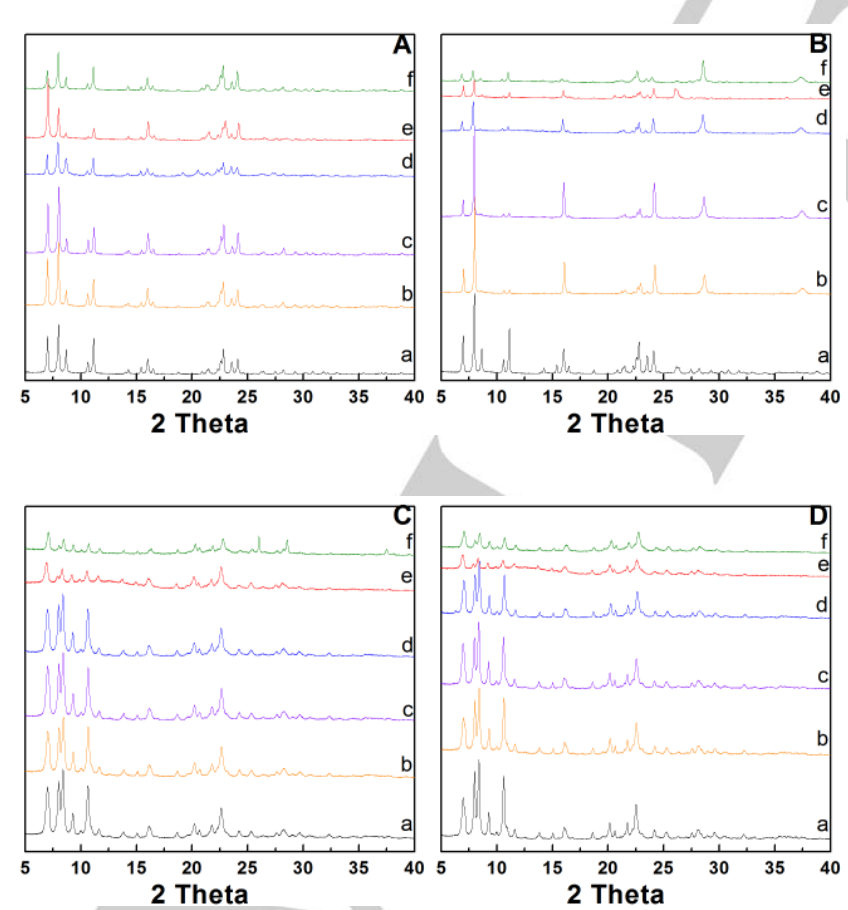

Figure 8. XRD patterns of ITH-13 (A), ITH-2 (B), IWW-7 (C), IWW-3 (D): calcined zeolites (a), asZeolite/Al/calc (b), asZeolite/HCl/Al/calc (c), asZeolite/HCl+TEOS/Al/calc (d), calcZeolite/Al (e), calcZeolite/HCl+TEOS/Al (f).
$6 / H C l+T E O S / A l$ with water did not cause any structural transformation of the zeolite (Figure S5, Supporting information). This is consistent with the lower reactivity of $\mathrm{Si}-\mathrm{O}-\mathrm{Si}$ and $\mathrm{Si}-\mathrm{O}-$ Al vs. Si-O-Ge bonds. ${ }^{[31]}$

As-synthesized ITH and IWW zeolites. XRD patterns of ITH and IWW subjected to the 1-step alumination or 2-step degermanation/alumination procedures (Figure 8) showed diffraction lines with slightly decreased intensities at the characteristic 2 theta positions. This indicated the preservation of the structural ordering of the respective zeolites with a decrease in framework density due to the leaching of $\mathrm{Ge}$ atoms (Table S1, Supporting information). The appearance of additional diffraction lines at 20.6 and $26.1-27^{\circ}$ in the XRD pattern of Ge-rich ITH, when treated in the as-synthesized form or when degermanated in ethanolic $\mathrm{HCl}$ solution, was attributed to a crystalline phase of $\mathrm{GeO}_{2}$.

Similarly to UTL, post-synthesis treatment of SDAcontaining ITH and IWW did not result in a substantial change in the $\mathrm{Si} / \mathrm{Ge}$ ratio (Table S1, Supporting information). Thus, slightly acidic environments seem to be inappropriate for the deep degermanation of SDA-containing zeolites with a 1-dimensional location of Ge-enriched domains.

In contrast to the medium-pore zeolite ITH (Figure 2A and $\mathrm{B})$, alumination of as/WW zeolites was less hindered by crystal size (Figure 2C, D) and led to the formation of acid centres. However these were in limited amounts $\left(17-59 \mu \mathrm{mol} \mathrm{g}^{-1}\right)$ when compared with the post-synthesis treatment of SDA-free zeolites (516 - $757 \mu \mathrm{mol} \mathrm{g}{ }^{-1}$, Table S1, Supporting information). The 
characteristics of modified SDA-free germanosilicates is discussed in details vide infra.

SDA-free ITH and IWW zeolites. ${ }^{27} \mathrm{AI}$ MAS NMR spectra of calc/TH/Al and calc/WW/Al samples (Figure S6, Supporting information) show the dominating peak (shift ranges of $50-80$ $\mathrm{ppm}$ ) corresponding to the framework tetrahedral $\mathrm{AlO}_{4}$ species and a smaller peak $(-10-15 \mathrm{ppm})$ assigned to octahedral $\mathrm{AlO}_{6}$ extra-framework species. The increased absorption band at $3745 \mathrm{~cm}^{-1}$ in the FTIR spectra of calcZeolite/Al with respect to the parent germanosilicate (Figure S7, Supporting information) agrees with the breaking of the hydrolytically unstable $\mathrm{Si}-\mathrm{O}-\mathrm{Ge}$ linkages and the formation of a non-equivalent amount of bridging Si-O-Al bonds (absorption band at $3620 \mathrm{~cm}^{-1}$, Figure S7, Supporting information).

Ge-rich ITH-2 has Ge atoms located both in the D4R units and $\left[4^{1} 5^{2} 6^{2}\right]$ cages $^{[20,32]}$ and showed a greater loss of $\mathrm{Ge}$ than Ge-poor ITH-13 (77\% vs $33 \%$ respectively) during the postsynthesis alumination (Table 2). This may be connected with a more rapid leaching of $\mathrm{Ge}$ atoms from the $\left[4^{1} 5^{2} 6^{2}\right]$ intralayer cages in comparison to the D4Rs. As the location of the $\left[4^{1} 5^{2} 6^{2}\right]$ intralayer cages, at the intersection of 9- and 10-ring pores, makes them more accessible than the D4Rs, which are only accessible from the 10-ring channels of ITH.
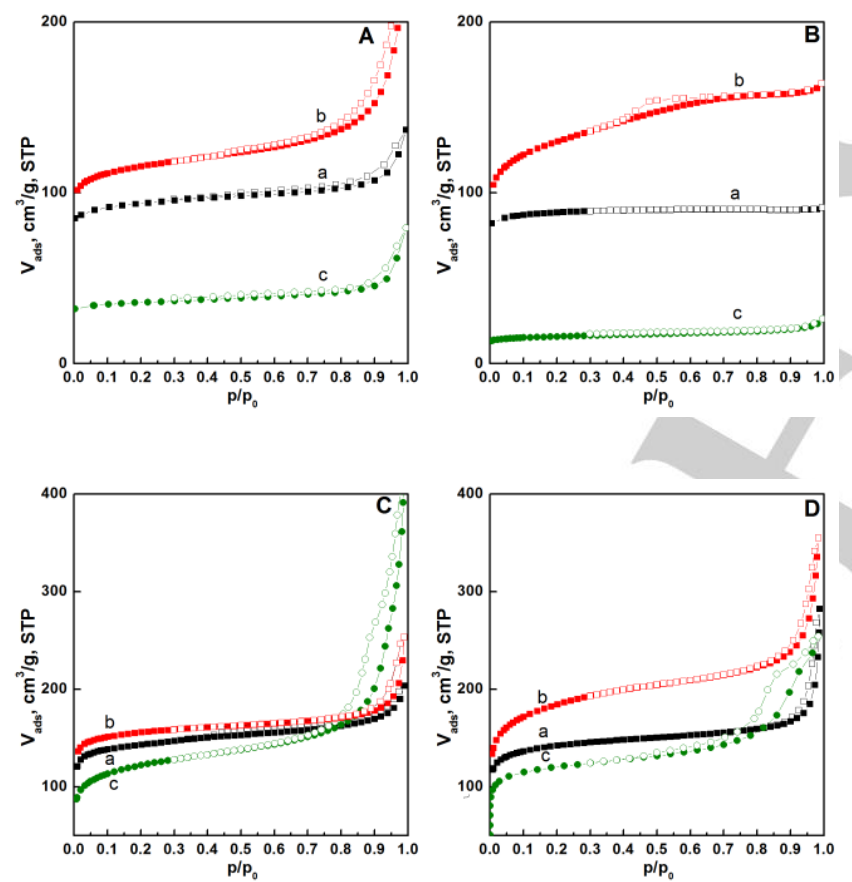

Figure 9. Nitrogen adsorption (•) and desorption (०) isotherms of $I T H-13(\mathbf{A})$, ITH-2 (B), IWW-7 (C) and IWW-3 (D): calcined zeolites (a), calcZeolite/AI (b), calcZeolite/HCl+TEOS/AI (c).

The decrease in the Ge content of aluminated ITH-13 (by $2.3 \mathrm{~mol}$. \% in calc/TH-13/Al) and IWW-7 (by $9.7 \mathrm{~mol}$. \% in calc/WW-7/Al) roughly corresponds to the amount of incorporated Al (1.8 mol. \% for calc/TH-13/Al and $6.8 \mathrm{~mol}$. \% for calc/WW-7/AI (Table 2)). In contrast to Ge-poor ITH-13 and IWW-7 zeolites, the amount of Ge extracted from ITH-2 (19.0 mol. \%) and IWW-3 (21.4 mol. \%) samples remarkably exceeded the concentration of the incorporated Al (1.3 - 6.5 mol. \%, Table 2). Despite the inconsistency in the amount of extracted/incorporated framework atoms, XRD data indicated the maintenance of interlayer bonds and structural ordering of Ge-rich IWW-3 and ITH-2 after alumination. In the absence of $\mathrm{Al}$, a full breaking of interlayer linkages took place under similar conditions (Figure 3B).

In contrast to IWW-3, Ge-poor IWW-7 showed the total substitution of Ge for Al. IWW-7 possesses D4R units containing $4 \mathrm{Ge}^{\left[{ }^{[13]}\right.}$ evenly distributed to avoid the formation of $\mathrm{Ge}-\mathrm{O}-\mathrm{Ge}$ bonds. Thus Ge-poor IWW materials were unaffected by the Löwenstein rule during the alumination procedure. ${ }^{[33]}$ Chemical analysis showed that about $70 \%$ of Ge leached from IWW-7 samples was substituted with Al atoms in callWW-7/Al (Table 2), enabling the maintenance of interlayer linkages.

Ge-poor calc/TH-13/Al and calc/WW-7/Al exhibited type I adsorption/desorption isotherms similar to their parent zeolites, but had a higher uptake in the range of filling micropores (Figure $9 \mathrm{~A}$ and $\mathrm{C}$ ). Ge-rich calcZeolite/Al samples were characterized by an increase in both the micropore and mesopore volumes (Table 2). The formation of mesopores is assumed to be connected with the higher degree of degermanation in Ge-rich samples and the non-equivalent replacement of leached Ge for Si/Al (Table 2). Such development of mesoporosity during alumination of the samples with high content of $\mathrm{Ge}$ can be considered as advantage of the proposed method since it allows not only to incorporate reasonable amount of potential active sites, but also to create additional transport pores usually facilitating catalytic transformation of bulk molecules. ${ }^{[34]}$

Noticeably, calcZeolite/HCl+TEOS/Al samples prepared using a 2-step degermanation/alumination treatment (Scheme 1, procedure 2) showed lower adsorption characteristics (Table 2) in comparison with calcZeolite/Al zeolites (Scheme 1, procedure 1). For calc/TH-2/HCl+TEOS/Al there was a significant drop in micropore volume $\left(\mathrm{V}_{\text {micro }}=0.02 \mathrm{~cm}^{3} \cdot \mathrm{g}^{-1}\right)$ in comparison with calc/TH-2/Al $\left(\mathrm{V}_{\text {micro }}=0.13 \mathrm{~cm}^{3} \cdot \mathrm{g}^{-1}\right.$, Table 2, vide infra) that may be connected to the undesired deposition of silica/ $\mathrm{GeO}_{2}$ in the relatively narrow pores of ITH. This phenomenon is less pronounced for large-pore IWW and especially extra-large-pore UTL zeolites subjected to 2-step alumination procedure using TEOS (Table 2). The results also show the slower rate of diffusion for Ge-containing species leached from medium-pore ITH in ethanolic vs. aqueous medium. Similarly to calcUTL$6 / H C l+T E O S / A l$, IWW samples prepared using a 2-step degermanation/alumination treatment (Scheme 1, procedure 2) showed isotherms with a steep rise at $\mathrm{p} / \mathrm{p}_{0}>0.05$ (Figure $9 \mathrm{C}$ and D).

Alumination resulted in the generation of a remarkably high number of acid sites in large-pore calc/WW/Al $(711-757 \mu \mathrm{mol}$ $\mathrm{g}^{-1}$, Table 2) vs. medium-pore calc/TH/Al zeolites $(211-330$ $\mu \mathrm{mol} \mathrm{g}^{-1}$, Table 2). This is due to the lower efficiency of alumination for medium-pore zeolites as the inner pores are poorly accessible for bulky hydrated aluminium cations. ${ }^{[26]}$ The decreased concentration of silanol defects (Figure S7, Supporting information) and lower amount of incorporated acid sites in calcZeolite/HCl+TEOS/Al vs. calcZeolite/Al (Table 2) is consistent with partial substitution of $\mathrm{Si}$ for $\mathrm{Ge}$ in calcZeolite/HCl+TEOS/AI.

Hydrothermal stability test showed the improved performance of aluminated calc/TH-2/Al, calcWW-3/Al, calcUTL$6 / \mathrm{HCl}+$ TEOS/Al zeolites in comparison with parent germanosilicates destructing under hydrothermal conditions (Figure S8, Supporting information). 


\begin{tabular}{|c|c|c|c|c|c|c|}
\hline \multirow[b]{2}{*}{ Pore size } & \multirow[b]{2}{*}{ Zeolite } & \multicolumn{5}{|c|}{ Procedure } \\
\hline & & 1 & 2 & 3 & 4 & 5 \\
\hline \multirow{2}{*}{ Medium } & ITH-13 & & & & & \\
\hline & ITH-2 & & & & & \\
\hline \multirow[t]{2}{*}{ Large } & IWW-7 & & & & & \\
\hline & IWW-3 & & & & & \\
\hline Extra- & UTL-6 & & & & & \\
\hline large & UTL-4 & & & & & \\
\hline
\end{tabular}

Scheme 2. Post-synthesis alumination of germanosilicate zeolites: acidity vs characteristics of parent germanosilicates / treatment procedure (deeper color means higher concentration of formed acid centers, hatched areas correspond to samples collapsed upon treatment).

\section{Catalytic performance of aluminated germanosilicates in tetrahydropyranylation of 1-propanol}

The catalytic behavior of aluminated germanosilicate zeolites was investigated in a model reaction of 1-propanol tetrahydropyranylation. While negligible conversion of alcohol $(2$ - $5 \%$ after $24 \mathrm{~h}$ ) was observed over parent germanosilicate zeolites containing only a small amount of weak Lewis acid centres (Table 2), both calcZeolite/Al and calcZeolite/HCl+TEOS/Al samples showed the selective transformation of 1-propanol into the targeted tetrahydropyranyl ether (Figure 10).

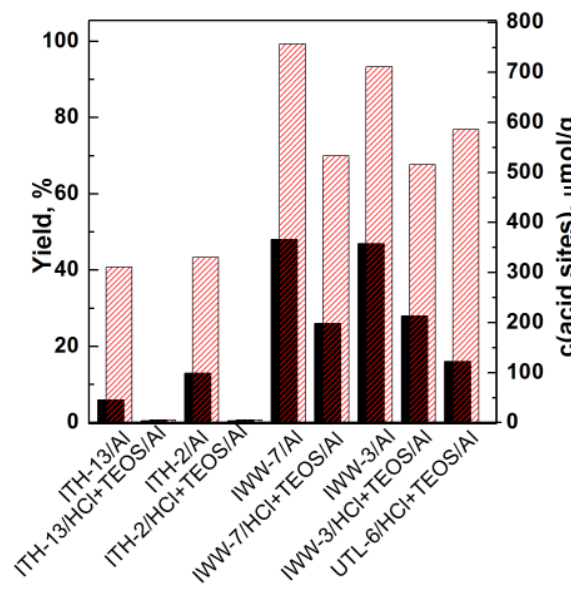

Figure 10. The yield of ether formed after $\tau=60 \mathrm{~min}$ in tetrahydropyranylation of 1-propanol over aluminated germanosilicate zeolites possessing $\left({ }^{2}\right)$ acid sites.

In general, calcZeolite/Al zeolites possessing more acid centers showed higher yields in comparison with calcZeolite/HCl+TEOS/Al (Fig 10). For instance, the increase in the concentration of acid sites in calc/WW-3/Al $\left(711 \mu \mathrm{mol} \mathrm{g}^{-1}\right) v s$. calc/WW-3/HCl+TEOS/Al $\left(516 \mu \mathrm{mol} \mathrm{g}^{-1}\right)$ was accompanied with enhancing yield from up to $47 \%$ (Figure 10). Lower activity of calcUTL-6/HCl+TEOS/Al vs. calc/WW/Al zeolites having similar concentration of acid sites (516 - 533 $\mu \mathrm{mol} \mathrm{g}^{-1}$, Table 2) is consistent with larger size of crystals characteristic for UTL (Fig. 2 , E) in which 12- and 14-R channels occurring along the longest dimensions $(25 \times 20 \mu \mathrm{m}$, Table 1), e.g. longer diffusion path of reacting molecules to the active centers. No conversion of 1-propanol was observed over calc/TH/HCl+TEOS/A/ samples having no incorporated acid sites (Table S1) and poor adsorption characteristics (Table 2).

\section{Conclusions}

The post-synthesis treatment of medium-pore ITH (Si/Ge = 2 13) and large-pore IWW ( $\mathrm{Si} / \mathrm{Ge}=3-7)$ zeolites can be used to control the degree of Ge-to-Al substitution and textural properties of resulting materials by choosing the appropriate chemical composition of parent zeolite and alumination conditions. The amount of $\mathrm{Ge}$ extracted from Ge-rich IWW $(\mathrm{Si} / \mathrm{Ge}=3)$ drastically exceeded the concentration of incorporated $\mathrm{Al}(30 \%)$, while $70 \%-78 \%$ of the Ge leached from Ge-poor IWW (Si/Ge = 7) and ITH (Si/Ge = 13) was replaced with $\mathrm{Al}$ atoms. Alumination resulted in the generation of a significantly higher number of acid sites in large-pore IWW $\left(711-757 \mu \mathrm{mol} \mathrm{g}^{-1}\right)$ compared to medium-pore ITH $(211-330$ $\left.\mu \mathrm{mol} \mathrm{g}^{-1}\right)$, indicating diffusion control of the alumination process (Scheme 2).

Conversely, in zeolite UTL $(\mathrm{Si} / \mathrm{Ge}=4-6)$ the hydrolysis of interlayer $\mathrm{Ge}-\mathrm{O}$ bonds is typically dominated process and only the application of the modified 2-step degermanation/alumination treatment allowed the partial substitution of Ge for Al. The aluminated UTL not only preserved its structure, but in addition a remarkable amount of Brønsted $\left(222 \mu \mathrm{mol} \mathrm{g}{ }^{-1}\right)$ and Lewis $\left(364 \mu \mathrm{mol} \mathrm{g}^{-1}\right)$ acidity was generated.

Non-equivalent exchange of $\mathrm{Ge}$ for $\mathrm{Al}$ in ITH $(\mathrm{Si} / \mathrm{Ge}=2)$, IWW $(\mathrm{Si} / \mathrm{Ge}=3)$ and UTL $(\mathrm{Si} / \mathrm{Ge}=6)$ allowed modification of textural characteristics of Ge-rich zeolites ended up forming hydrolytically stable hierarchical micro-mesoporous aluminosilicates.

The activity of prepared Al-substituted zeolites possessing the same topology/crystals in tetrahydropyranylation of 1propanol was found enhancing with increasing total concentration of incorporated acid centers.

The developed methods of stabilization/alumination may extend the practical application of germanosilicate zeolites, which have high potential for application in catalysis but limited hydrothermal stability. In addition, there exists the possibility of easy recovering of $\mathrm{Ge}$ from acidic solution applying one of the methods proposed in Refs. ${ }^{[35]}$.

\section{Experimental Section}

Synthesis of Zeolites. Samples of ITH, IWW, and UTL were prepared following the literature procedures ${ }^{[6,22 b, 24,36]}$ using hexamethonium (HM), N,N,N',N'-tetramethyl-1,6-hexanediamine (TMHDA), 1,5bis(methylpyrrolidinium)-pentane (MPP), and (6R,10S)-6,10-dimethyl-5azoniaspiro[4,5]decane (DMAD) cations as structure directing agents.

For Ge-poor ITH (Si/Ge = 13.3 according to chemical analysis), germanium oxide $\left(\mathrm{GeO}_{2}, 99.99 \%\right.$, Aldrich) was first dissolved in a $1 \mathrm{M}$ solution of $\mathrm{HM}$ dihydroxide followed by the addition of tetraethyl orthosilicate (TEOS, $98 \%$, Aldrich). The mixture was stirred at room temperature until water/ethanol was evaporated. Resulting in a gel with the composition $0.90 \mathrm{SiO}_{2}: 0.09 \mathrm{GeO}_{2}: 0.25 \mathrm{HM}: 5 \mathrm{H}_{2} \mathrm{O}$. This was 
transferred into a Teflon-lined autoclave and heated at $175{ }^{\circ} \mathrm{C}$ for 14 days under slow stirring (60 rpm). ${ }^{[24]}$

Ge-rich ITH (Si/Ge = 2.3 according to chemical analysis) was crystallized using TMHDA as the structure-directing agent in the presence of fluorine anions according to Ren et al. ${ }^{[36]}$ The synthetic suspension with the composition $0.5 \mathrm{SiO}_{2}: 0.5 \mathrm{GeO}_{2}: 7 \mathrm{TMHDA}: 1.4 \mathrm{HF}: 44 \mathrm{H}_{2} \mathrm{O}$ was then heated at $175^{\circ} \mathrm{C}$ for 6 days under static conditions.

IWW samples were prepared using MPP dihydroxide as the SDA according to Ref. ${ }^{[6]}$ A gel composition of $(1-\mathrm{x}) \mathrm{SiO}_{2}: \mathrm{x} \mathrm{GeO}_{2}: 0.25 \mathrm{MPP}$ : $10 \mathrm{H}_{2} \mathrm{O}$ was achieved, where $\mathrm{x}=0.33$ for Ge-rich IWW $(\mathrm{Si} / \mathrm{Ge}=2.9$ according to chemical analysis) and $x=0.2$ for Ge-poor IWW (Si/Ge = 7.2 according to chemical analysis), respectively. The reaction mixture was then heated at $175^{\circ} \mathrm{C}$ for 7 days.

UTL samples were prepared according to Ref. ${ }^{[22 b]}$ by the crystallization of a gel with the composition of (1-x) $\mathrm{SiO}_{2}: x \mathrm{GeO}_{2}: 0.25$ DMAD : $30 \mathrm{H}_{2} \mathrm{O}$ at $175^{\circ} \mathrm{C}$ for 6 days under agitation $(60 \mathrm{rpm})$, where $\mathrm{x}=0.33$ for Ge-rich UTL ( $\mathrm{Si} / \mathrm{Ge}=3.8$ according to chemical analysis) and $\mathrm{x}=0.17$ for $\mathrm{Ge}$ poor UTL ( $\mathrm{Si} / \mathrm{Ge}=6.0$ according to chemical analysis), respectively.

The solid products of hydrothermal synthesis were separated by filtration, washed out with distilled water, and dried overnight at $95^{\circ} \mathrm{C}$.

Obtained zeolites were designated as ITH-y, IWW-y, UTL-y, where y is $\mathrm{Si} / \mathrm{Ge}$ ratio in the sample.

Post-synthesis treatment of calcined zeolites. Before the treatment germanosilicate zeolites under investigation were calcined according to Ref. ${ }^{[22 b, 36-37]}$ IWW, UTL and Ge-poor ITH samples were calcined at $550{ }^{\circ} \mathrm{C}$, while Ge-rich ITH was calcined at $650{ }^{\circ} \mathrm{C}$ for $6 \mathrm{~h}$ with a temperature ramp of $1^{\circ} \mathrm{C} \cdot \mathrm{min}^{-1}$.

Procedure 1 (Scheme 1). $0.5 \mathrm{~g}$ of calcined zeolite was treated with $50 \mathrm{~mL}$ of $1 \mathrm{M} \mathrm{Al}\left(\mathrm{NO}_{3}\right)_{3}$ solution at $80^{\circ} \mathrm{C}$ for $24 \mathrm{~h}$. The aluminated samples were subsequently filtrated and washed sequentially with $0.01 \mathrm{M} \mathrm{HCl}$ and deionized water and designated as calcZeolite-y/Al.

Procedure 2 (Scheme 1). $0.5 \mathrm{~g}$ of calcined zeolite was treated with $50 \mathrm{~mL}$ of ethanolic $1 \mathrm{M} \mathrm{HCl}$ solution. Under stirring, an additional Si source was added into the mixture $\left(1 \mathrm{mmol}\right.$ of TEOS per $1 \mathrm{gram}$ of zeolite $\left.{ }^{[17]}\right)$. The mixture was stirred for $0.5 \mathrm{~h}$ at room temperature, then transferred to Teflon-lined autoclaves and heated at $170{ }^{\circ} \mathrm{C}$ for $24 \mathrm{~h}$. After the treatment, the zeolites were filtered and washed sequentially with ethanol and water, air-dried at room temperature before being subjected to alumination at $80{ }^{\circ} \mathrm{C}$ for $24 \mathrm{~h}$. The aluminated samples were subsequently filtrated and washed with $0.01 \mathrm{M} \mathrm{HCl}$ and deionized water and designated as calcZeolite-y/HCl+TEOS/AI.

\section{Post-synthesis treatment of as-made zeolites.}

Procedure 3 (Scheme 1). The as-made zeolite was treated as described in Procedure 1. The samples were designated as asZeolite-y/Al.

Procedure 4 (Scheme 1). $0.5 \mathrm{~g}$ of as-made zeolite was treated with 50 $\mathrm{mL}$ of $1 \mathrm{M} \mathrm{HCl}$ solution. The mixture was stirred for $0.5 \mathrm{~h}$ at ambient temperature and then transferred to Teflon-lined autoclaves and heated at $170{ }^{\circ} \mathrm{C}$ for $24 \mathrm{~h}$. After the treatment, the zeolites were washed with water and air-dried at room temperature. The dried samples were then subjected to alumination with $50 \mathrm{~mL}$ of $1 \mathrm{M} \mathrm{Al}\left(\mathrm{NO}_{3}\right)_{3}$ solution at $80^{\circ} \mathrm{C}$ for $24 \mathrm{~h}$. The samples were designated as asZeolite-y/HCl/Al.

Procedure 5 (Scheme 1). As-made zeolite was treated as described in Procedure 2. The samples were designated as asZeolite- $y / \mathrm{HCl}+\mathrm{TEOS} / \mathrm{Al}$.
The aluminated samples were subsequently filtered and washed with $0.01 \mathrm{M} \mathrm{HCl}$ and deionized water before being calcined at $550-650{ }^{\circ} \mathrm{C}$, for $6 \mathrm{~h}$ with a temperature ramp of $1^{\circ} \mathrm{C} \cdot \mathrm{min}^{-1}$ according to Ref. ${ }^{[22 b, 36-37]}$ to remove organic SDA

Hydrolytic stability test. Calcined zeolites were hydrolyzed in a $0-0.01$ $\mathrm{M}$ solution of nitric acid at $25^{\circ} \mathrm{C}$ for $24 \mathrm{~h}$ with a w/w ratio $1 / 100$. The hydrolyzed material was isolated by centrifugation, washed out with deionized water and dried at $25^{\circ} \mathrm{C}$. Zeolites, treated with $0.01 \mathrm{M} \mathrm{HNO}_{3}$ were designated as calcZeolite- $y / \mathrm{HNO}_{3}$.

Hydrothermal stability test. Calcined zeolites were treated in water at $100{ }^{\circ} \mathrm{C}$ for $24 \mathrm{~h}$ with a w/w ratio $1 / 100$. The hydrolyzed material was isolated by centrifugation and dried at $25^{\circ} \mathrm{C}$.

Characterization. The crystallinity of all samples under investigation was determined by X-ray powder diffraction (XRD) using a Bruker AXS-D8 Advance diffractometer with a graphite monochromator and a position sensitive detector (Våntec-1) using CuKa radiation in Bragg-Brentano geometry at a scan rate of $0.25^{\circ} 2 \theta$ min- 1 .

The concentration of $\mathrm{Al}, \mathrm{Ge}$ and $\mathrm{Si}$ was determined by energy dispersive X-ray spectroscopy (EDX) on a Jeol JSM 5600 instrument.

Nitrogen adsorption/desorption isotherms were measured using an ASAP 2020 (Micromeritics) static volumetric apparatus at $-196{ }^{\circ} \mathrm{C}$. Prior to the sorption measurements, all samples were degassed with a turbo molecular pump at $300^{\circ} \mathrm{C}$ for $8 \mathrm{~h}$. Micropore size distribution was evaluated using the NLDFT method ( $\mathrm{Ar}$ on oxides at $87 \mathrm{~K}$ kernel) based on the data collected by $\mathrm{Ar}$ adsorption at $-186^{\circ} \mathrm{C}$.

The size and morphology of the zeolite crystals were examined by scanning electron microscopy (SEM, JEOL JSM-5500LV microscope). For these measurements the crystals were coated with a thin layer of platinum $(\sim 10 \mathrm{~nm})$ in a BAL-TEC SCD-050 instrument.

Solid-state ${ }^{27} \mathrm{Al}$ NMR spectra were obtained using a Bruker Advance III spectrometer, equipped with a $9.4 \mathrm{~T}$ wide-bore superconducting magnet (1H Larmor frequency of $400.13 \mathrm{MHz}$ ). The samples were packed into a conventional $4 \mathrm{~mm}$ zirconia rotor and rotated at a MAS rate of $12.5 \mathrm{kHz}$ using a Bruker $4 \mathrm{~mm}$ HFXY probe. A pulse of $1.5 \mu \mathrm{s}(\mathrm{v} 1 \approx 100 \mathrm{kHz}$ ) was applied. Signal averaging was carried out for 200 transients with a repeat interval of $2 \mathrm{~s}$. Spectra were referenced to $1.1 \mathrm{M} \mathrm{Al}\left(\mathrm{NO}_{3}\right)_{3}$ in $\mathrm{D}_{2} \mathrm{O}$ using solid $\mathrm{Al}(\mathrm{acac})_{3}\left(\delta_{\text {iso }}=0 \mathrm{ppm}\right.$, centre of gravity $=-4.2 \mathrm{ppm}$ at $\left.9.4 \mathrm{~T}\right)$ as a secondary reference.

The concentration of Lewis (cL) and Brønsted (cB) acid sites was determined after adsorption of $d_{3}$-acetonitrile $(A C N)$ by FTIR spectroscopy using a Nicolet Protégé 460 Magna with a transmission DTGS detector. The zeolites were pressed into self-supporting wafers with a density of $8.0-12 \mathrm{mg} \mathrm{cm}^{-2}$ and activated in situ at $\mathrm{T}=450{ }^{\circ} \mathrm{C}$ and $p=5 \cdot 10-5$ Torr for $4 \mathrm{~h}$. ACN adsorption was carried out at ambient temperature for $30 \mathrm{~min}$ at a partial pressure of 5 Torr, followed by desorption for $20 \mathrm{~min}$ at the same temperature. Before adsorption ACN was degassed by freezing-pump-thaw cycles. All spectra were recorded with a resolution of $4 \mathrm{~cm}^{-1}$ by collecting 128 scans for a single spectrum at room temperature. Spectra were recalculated using a wafer density of $10 \mathrm{mg} \mathrm{cm}^{-2}$. Concentration of $C_{L}$ and $C_{B}$ were evaluated from the integral intensities of bands at $2323 \mathrm{~cm}^{-1}\left(\mathrm{CL}_{\mathrm{L}}\right)$ and at $2294 \mathrm{~cm}^{-1}\left(\mathrm{C}_{\mathrm{B}}\right)$ using

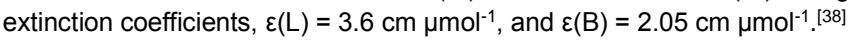

\section{Tetrahydropyranylation of 1-propanol.}

The catalytic experiments were performed in the liquid phase under atmospheric pressure at room temperature $\left(25^{\circ} \mathrm{C}\right)$ in a multi-experiment workstation Star-Fish (Radleys Discovery Technologies). Before using, the catalyst $(100 \mathrm{mg})$ was activated at $450{ }^{\circ} \mathrm{C}$ for $120 \mathrm{~min}$ at a rate of 
$10{ }^{\circ} \mathrm{C} / \mathrm{min}$. Typically, 1-propanol $(9 \mathrm{mmol})$, mesitylene $(0.2 \mathrm{~g}$; internal standard), hexane $(10 \mathrm{~mL}$, solvent) and the catalyst $(100 \mathrm{mg})$ were added to a two-necked vessel equipped with a thermometer. DHP (15 $\mathrm{mmol})$ was then added to the vessel. Samples of the reaction mixture were taken periodically and analyzed by using Agilent $6850 \mathrm{GC}$ equipped a polar DB-WAX column (length $20 \mathrm{~m}$, diameter $0.180 \mathrm{~mm}$, and film thickness $0.3 \mu \mathrm{m}$ ) and flame ionization detector.

The reaction product was identified by using Thermo Finnigan Focus DSQ II Single Quadrupole GC/MS.

[1] a) A. Corma, M. T. Navarro, F. Rey, J. Rius, S. Valencia, Angew. Chem., Int. Ed. 2001, 40, 2277-2280; b) G. Sastre, J. A. Vidal-Moya, T Blasco, J. Rius, J. L. Jordá, M. T. Navarro, F. Rey, A. Corma, Angew. Chem., Int. Ed. 2002, 41, 4722-4726; c) J. Jiang, J. Yu, A. Corma, Angew. Chem., Int. Ed. 2010, 49, 3120-3145; d) A. Corma, M. J. Diaz Cabanas, J. Jiang, M. Afeworki, D. L. Dorset, S. L. Soled, K. G. Strohmaier, Proc. Natl. Acad. Sci. U. S. A. 2010, 107, 13997-14002; e) J. Jiang, J. L. Jorda, M. J. Diaz-Cabanas, J. Yu, A. Corma, Angew. Chem., Int. Ed. 2010, 49, 4986-4988.

[2] T. Conradsson, M. S. Dadachov, X. D. Zou, Microporous Mesoporous Mater. 2000, 41, 183-191.

[3] H. L. Li, O. M. Yaghi, J. Am. Chem. Soc. 1998, 120, 10569-10570.

[4] R. Castañeda, A. Corma, V. Fornes, F. Rey, J. Rius, J. Am. Chem. Soc. 2003, 125, 7820-7821.

[5] D. L. Dorset, K. G. Strohmaier, C. E. Kliewer, A. Corma, M. J. DíazCabañas, F. Rey, C. J. Gilmore, Chem. Mater. 2008, 20, 5325-5331.

[6] A. Corma, F. Rey, S. Valencia, J. L. Jorda, J. Rius, Nat. Mater. 2003, 2, 493-497.

[7] J. Sun, C. Bonneau, A. Cantin, A. Corma, M. J. Diaz-Cabanas, M. Moliner, D. Zhang, M. Li, X. Zou, Nature 2009, 458, 1154-1157.

[8] a) J. L. Paillaud, B. Harbuzaru, J. Patarin, N. Bats, Science 2004, 304 , 990-992; b) A. Corma, M. J. Diaz-Cabanas, F. Rey, S. Nicolooulas, K. Boulahya, Chem. Commun. (Cambridge, U. K.) 2004, 1356-1357.

[9] A. Corma, M. J. Diaz-Cabanas, J. L. Jorda, F. Rey, G. Sastre, K. G. Strohmaier, J. Am. Chem. Soc. 2008, 130, 16482-16483.

[10] M. Dodin, J.-L. Paillaud, Y. Lorgouilloux, P. Caullett, E. Elkaim, N. Bats, J. Am. Chem. Soc. 2010, 132, 10221-10223.

[11] a) M. O'Keeffe, O. M. Yaghi, Chem. Eur. J. 1999, 5, 2796-2801; b) T. Blasco, A. Corma, M. J. Diaz-Cabanas, F. Rey, J. A. Vidal-Moya, C. M. Zicovich-Wilson, J. Phys. Chem. B 2002, 106, 2634-2642; c) G. Sastre, A. Pulido, A. Corma, Microporous Mesoporous Mater. 2005, 82, 159 163

[12] a) W. J. Roth, O. V. Shvets, M. Shamzhy, P. Chlubna, M. Kubu, P. Nachtigall, J. Čejka, J. Amer. Chem. Soc. 2011, 133, 6130-6133; b) M. Mazur, P. S. Wheatley, M. Navarro, W. J. Roth, M. Položij, A. Mayoral P. Eliášová, P. Nachtigall, J. Čejka, R. E. Morris, Nat. Chem. 2016, 8 58-62.

[13] P. Chlubná-Eliášová, Y. Tian, A. B. Pinar, M. Kubů, J. Čejka, R. E. Morris, Angew. Chem., Int. Ed. 2014, 53, 7042-7052.

[14] L. Tang, L. Shi, C. Bonneau, J. Sun, H. Yue, A. Ojuva, B.-L. Lee, M. Kritikos, R. G. Bell, Z. Bacsik, J. Mink, X. Zou, Nat. Mater. 2008, 7, 381 385.

[15] F. Gao, M. Jaber, K. Bozhilov, A. Vicente, C. Fernandez, V. Valtchev, J. Am. Chem. Soc. 2009, 131, 16580-16586.

[16] L. Burel, N. Kasian, A. Tuel, Angew. Chem., Int. Ed. 2014, 53, 13601363.

[17] H. Xu, J.-g. Jiang, B. Yang, L. Zhang, M. He, P. Wu, Angew. Chem., Int Ed. 2014, 53, 1355-1359.

[18] a) M. Shamzhy, F. S. d. O. Ramos, Catal. Today 2015, 243, 76-84; b) P Eliášová, M. Opanasenko, P. S. Wheatley, M. Shamzhy, M. Mazur, P. Nachtigall, W. J. Roth, R. E. Morris, J. Čejka, Chem. Soc. Rev. 2015 44, 7177-7206

[19] X. Liu, U. Ravon, F. Bosselet, G. Bergeret, A. Tuel, Chem. Mater. 2012 24, 3016-3022

[20] J. A. Vidal-Moya, T. Blasco, F. Rey, A. Corma, M. Puche, Chem. Mater 2003, 15, 3961-3963.

\section{Acknowledgements}

We acknowledge the valuable input from Dr Daniel Dawson and the University of St. Andrews Solid state NMR service. M.S. thanks the Czech Science Foundation for the support of the Project 14-30898P. R.E.M. thanks the EPSRC for funding through grant EP/K025112/1

Keywords: alumination • germanosilicate zeolites $\bullet$ ITH $・$ IWW UTL

[21] M. Shamzhy, M. Opanasenko, Y. Tian, K. Konysheva, O. Shvets, R. E. Morris, J. Čejka, Chem. Mater. 2014, 26, 5789-5798.

[22] a) O. V. Shvets, M. V. Shamzhy, P. S. Yaremov, Z. Musilova, D. Prochazkova, J. Čejka, Chem. Mater. 2011, 23, 2573-2585; b) M. V. Shamzhy, O. V. Shvets, M. V. Opanasenko, P. S. Yaremov, L. G. Sarkisyan, P. Chlubna, A. Zukal, V. R. Marthala, M. Hartmann, J. Čejka, J. Mater. Chem. 2012, 22, 15793-15803.

[23] N. Kasian, A. Tuel, E. Verheyen, C. E. A. Kirschhock, F. Taulelle, J. A Martens, Chem. Mater. 2014, 26, 5556-5565.

[24] R. Castañeda, A. Corma, V. Fornes, J. Martinez-Triguero, S. Valencia J. Catal. 2006, 238, 79-87.

[25] R. L. Smith, P. Eliasova, M. Mazur, M. P. Attfield, J. Cejka, M. W Anderson, Chem. Eur. J. 2014, 20, 10446-10450.

[26] a) C. Y. Chen, S. I. Zones, US 6,468,501, 2002; b) C.-Y. Chen, S. I. Zones, in Zeolites and Catalysis, Wiley-VCH Verlag $\mathrm{GmbH} \& \mathrm{Co}$. KGaA, 2010, pp. 155-170.

[27] M. Kosmulski, Chemical Properties of Material Surfaces, CRC Press, 2001

[28] L. Tosheva, N. Mahé, V. Valtchev, in Stud. Surf. Sci. Catal., Vol. 170 (Eds.: Z. G. J. C. Ruren Xu, Y. Wenfu), Elsevier, 2007, pp. 616-621.

[29] P. S. Wheatley, P. Chlubná-Eliášová, H. Greer, W. Zhou, V. R Seymour, D. M. Dawson, S. E. Ashbrook, A. B. Pinar, L. B. McCusker, M. Opanasenko, J. Čejka, R. E. Morris, Angew. Chem., Int. Ed. 2014 53, 13210-13214.

[30] in Multinuclear Solid-State NMR of Inorganic Materials, Vol. 6 (Eds.: J D. M. Kenneth, E. S. Mark), Pergamon, 2002, pp. 271-330.

[31] R. E. Morris, J. Čejka, Nat. Chem. 2015, 7, 381-388.

[32] M. Shamzhy, M. Opanasenko, Y. Tian, K. Konysheya, O. Shvets, R. E. Morris, J. Čejka, Chemistry of Materials 2014, 26, 5789-5798.

[33] R. Szostak, Molecular sieves: principles of synthesis and identification, Springer, 1998.

[34] C. Martinez, D. Verboekend, J. Perez-Ramirez, A. Corma, Catal. Sci. Tech. 2013, 3, 972-981.

[35] a) A. Hernandez-Exposito, J. M. Chimenos, A. I. Fernandez, O. Font, X Querol, P. Coca, F. G. Pena, Chem. Eng. J. (Lausanne) 2006, 118, 69 75; b) K. A. Matis, P. Mavros, Sep. Purif. Methods 1991, 20,1-48; c) J. P. Marco-Lozar, D. Cazorla-Amoros, A. Linares-Solano, Carbon 2007 45, 2519-2528; d) F. J. S. Menendez, F. M. S. Menendez, A. de Cuadra Herrera, F. A. Tamargo, L. P. Lorenzo, M. R. Valcarcel, V. A Fernandez, in US 4,886,648 (Ed.: US 4, 648), US 4,886,648, US 4,886,648, 1989

[36] X. Ren, J. Liu, Y. Li, J. Yu, R. Xu, J. Porous Mater. 2013, 20, 975-981.

[37] G. Sastre, A. Pulido, R. Castañeda, A. Corma, J. Phys. Chem. B 2004 108, 8830-8835

[38] B. Wichterlová, Z. Tvarůžková, Z. Sobalík, P. Sarv, Microporous Mesoporous Mater. 1998, 24, 223-233. 
Entry for the Table of Contents (Please choose one layout)

\section{FULL PAPER}

The stabilization of the extralarge pore zeolite UTL by the partial post-synthesis

substitution of $\mathrm{Ge}$ for $\mathrm{Si}$ and $\mathrm{Al}$ is reported for the first time.

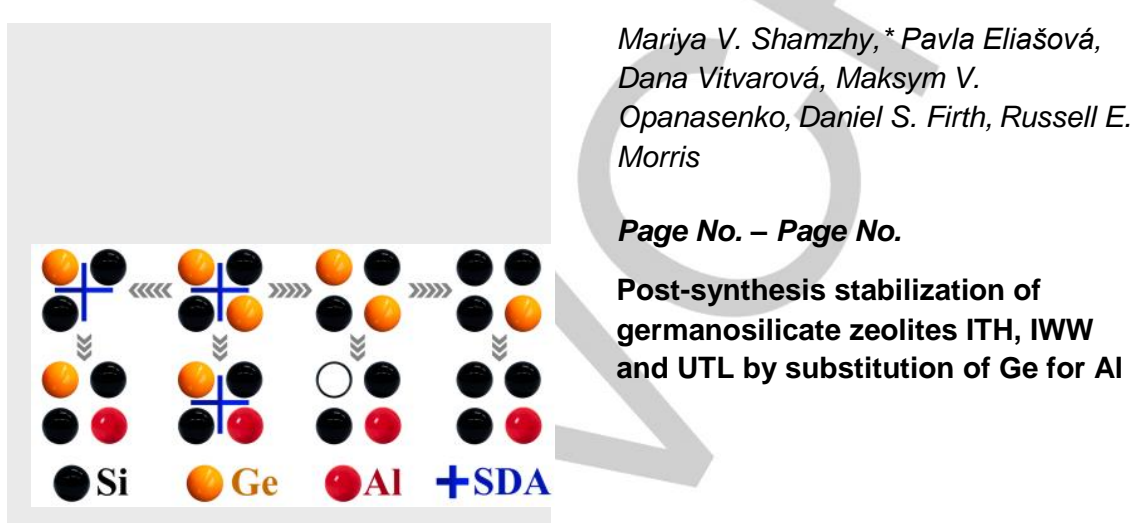

